\title{
ANALISIS LOKASI PERUMAHAN UNTUK MASYARAKAT BERPENGHASILAN RENDAH DI KOTA PALOPO
}

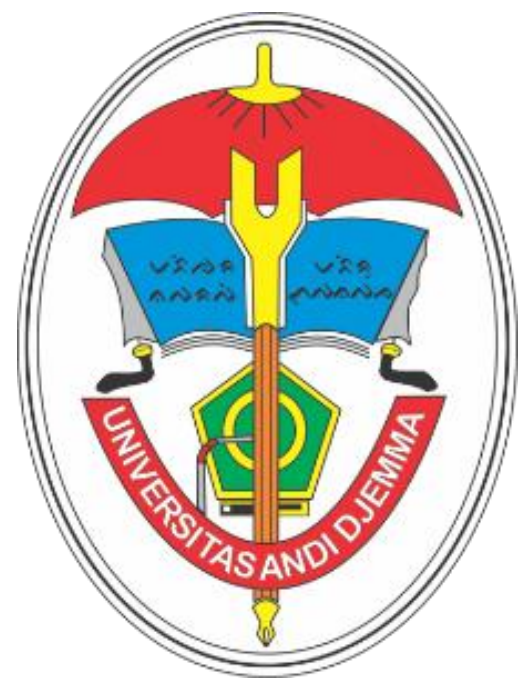

Disusun oleh :

\author{
Nama : Williams Reyditya \\ NIM : 18.023.22.201.014 \\ Kelas : Sipil 1
}

FAKULTAS TEKNIK

PROGRAM STUDI TEKNIK SIPIL

PALOPO

2021 


\section{KATA PENGANTAR}

Alhamdulillah dan puji syukur kami panjatkan kepada Allah SWT yang telah melimpahkan rahmat dan hidayah-Nya, sehingga penulis dapat menyusun dan menyelesaikan Tugas Akhir yang berjudul "Alternatif Lokasi Perumahan bagi Masyarakat Berpenghasilan Rendah di kota palopo" dengan lancer.

Saya menyadari bahwa dalam penyusunan laporan ini tidak terlepas dari beberapa kesalahan yang tidak saya sengaja. Segala masukan, berupa saran dan kritik yang membangun akan saya terima dengan tangan terbuka demi kemajuan kita bersama. Semoga laporan ini berguna bagi saya selaku penyusun dan bagi pembaca dalam mengembangkan ilmu-ilmu perencanaan pada masa yang akan datang. 


\section{BAB I}

\section{PENDAHULUAN}

\subsection{LATAR BELAKANG}

Pertumbuhan penduduk yang cenderung meningkat dari tahun ke tahun khususnya di wilayah Kota Palopo telah menimbulkan peningkatan permintaan terhadap kebutuhan akan tempat tinggal atau perumahan di perkotaan tak terkecuali bagi Masyarakat Berpenghasilan Rendah. Masyarakat Berpenghasilan rendah yang dimaksud adalah masyarakat yang memiliki keterbatasan dalam memiliki maupun membeli rumah. Fenomena yang terjadi saat ini adalah kurang tersedianya perumahan bagi masyarakat yang berpenghasilan rendah. Perumahan yang disediakan oleh pengembang dan pemerintah hanya mampu dijangkau oleh masyarakat berpenghasilan menengah dan atas.

Indonesia telah menetapkan dalam pasal 28 ayat 1 Undang-undang Dasar RI tahun 1945, bahwa setiap orang memiliki hak hidup sejahtera lahir dan bathin, bertempat tinggal dan mendapatkan lingkungan hidup yang baik dan sehat. Oleh karenanya, rumah sebagai wadah tempat tinggal perseorangan ataupun dalam entitas sosial, baik dalam bentuk keluarga atau lainnya merupakan hak setiap orang. Hak perumahan secara nasional didefinisikan sebagai kelengkapan rumah dengan jaminan keamanan dan hukum, jaminan perolehan prasarana, sarana dan utilitas dasar, akses pada pembiayaan, dan atau hal lain untuk memenuhi martabatnya sebagai manusia.

Menurut Badan Pusat Analisis Kota Palopo SP2020 mencatat penduduk kota palopo pada bulan September 2020 sebesar 184.681 jiwa. Dibandingkan dengan sensus sebelumnya, jumlah penduduk terus mengalami peningkatan. Dalam jangka waktu sepuluh tahun yaitu tahun 2010 hinggan 2020, jumlah penduduk Kota Palopo mengalami penambahan sekitar 36.749 jiwa atau rata - rata 3.674 jiwa setiap tahunnya. Seiring dengan pertumbuhan penduduk di Kota Palopo yang terus meningkat dengan kondisi lahan yang semakin sempit. Hal ini mendorong seseorang untuk lebih cepat mencari tempat tinggal, agar tidak perlu lagi bagi mereka mencari lahan untuk 
mendirikan rumah bahkan untuk membangunnya sendiri karena mereka tinggal membeli tipe atau bentuk rumah sesuai dengan kemampuannya membeli rumah tersebut.

Di Indonesia perumahan dikelola oleh dua pihak yakni pemerintah yang sering disebut "Perumnas" dan pihak swasta (PT atau CV) yang disebut "Perum". Perumahan yang dikelola oleh pemerintah dari segi harga lebih terjangkau dari pada perumahan milik swasta. Pembelian rumah dapat dilakukan dengan cara tunai ataupun kredit. Seseorang dapat membeli rumah secara tunai apabila orang tersebut memiliki uang yang nilainya sama dengan harga rumah tersebut. Namun, seiring dengan semakin sulitnya keadaan ekonomi dan banyaknya tuntutan kebutuhan yang harus dipenuhi oleh masyarakat maka pembelian rumah secara tunai semakin sulit dilakukan, terutama bagi masyarakat yang tingkat ekonominya menengah ke bawah. Masyarakat yang memiliki kesulitan dalam memenuhi kebutuhan perumahannya yaitu Masyarakat Berpenghasilan Rendah.

\subsection{RUMUSAN MASALAH}

Berdasarkan latar belakang masalah diatas maka yang menjadi permasalahan dalam penelitian ini adalah :

Bagaimana Implementasi Pemerintah Kota Palopo mengenai lokasi Perumahan bagi Masyarakat Berpenghasilan Rendah ?

\subsection{TUJUAN DAN MANFAAT PENELITIAN}

\section{A. TUJUAN PENELITIAN}

Berdasarkan rumusan masalah yang dikemukakan diatas, adapun tujuan yang hendak dicapai dari penelitian ini adalah untuk mengetahui implementasi Pemerintah Kota Palopo mengenai lokasi Perumahan bagi Masyarakat Berpenghasilan Rendah.

\section{B. MANFAAT PENELITIAN}

1. Sebagai masukan bagi Pemerintah Kota Palopo dalam mengembangkan pembangunan perumahan bagi Masyarakat Berpenghasilan Rendah . 
2. Sebagai penambahan ilmu pengetahuan bagi penulis terhadap pengembangan pembangunan bagi Masyarakat Berpenghasilan Rendah.

\subsection{BATASAN PENELITIAN}

Untuk mempermudah penulisan penelitiam ini dan agar lebih terarah serta berjalan dengan baik, maka perlu dikiranya dibuat suatu batasan masalah. Adapun Batasan Batasan permasalahan yang akan dibahas dalam penulisan penelitian ini, yaitu:

1. Memberikan pemahaman mengenai MBR.

2. Memberikan pemahaman mengenai peraturan atau standar yang di buat pemerintah bagi Masyarakat Berpenghasilan dalam memperoleh rumah.

3. Melakukan anilisis mengenai alternatif lokasi perumahan bagi Masyarakat Berpenghasilan Rendah di Kota Palopo. 


\section{BAB II}

\section{LANDASAN TEORI}

\subsection{MASYARAKAT BERPENGHASILAN RENDAH}

Masyarakat berpenghasilan rendah yang selanjutnya disingkat MBR adalah masyarakat yang mempunyai keterbatasan daya beli sehingga perlu mendapat dukungan pemerintah untuk memperoleh rumah (Pasal 1 Angka 24 UU Nomor 1 Tahun 2011 Tentang Perumahan dan Kawasan Permukiman). Masyarakat berpenghasilan rendah yang selanjutnya disebut MBR adalah masyarakat yang mempunyai keterbatasan daya beli sehingga perlu mendapat dukungan pemerintah untuk memperoleh sarusun umum (Pasal 1 Angka 14 UU Nomor 20 Tahun 2011 Tentang Rumah Susun).

Turner (1968) dalam Hutapea (2012) menyatakan bahwa terdapat kaitan antara kondisi ekonomi dengan tingkat prioritas kebutuhan perumahan pada setiap manusia. Bagi masyarakat golongan berpenghasilan rendah, terdapat 3 tingkat prioritas kebutuhan perumahan yaitu :

A. faktor jarak menjadi prioritas utama

B. faktor status lahan dan rumah menjadi prioritas kedua

C. faktor bentuk dan kualitas rumah menjadi prioritas ketiga

Menurut Wijaya dalam Budihardjo (2009) pembangunan permukiman bagi masyarakat berpenghasilan rendah bukan merupakan usaha yang terisolisir. Karena, pembangunan tersebut mempunyai multiplier effect yang besar, baik peningkatan industri dan jasa kota maupun penyediaan lapangan kerja baru.

Menurut Panudju (2009) dalam menentukan prioritas kebutuhan rumah, masyarakat golongan berpenghasilan rendah cenderung meletakkan prioritas utama pada lokasi rumah yang berdekatan dengan tempat yang dapat memberikan kesempatan kerja. Tanpa kesempatan kerja yang dapat menopang kebutuhan seharihari, sulit bagi mereka untuk dapat mempertahankan hidupnya. Status pemilikan rumah dan lahan menempati prioritas kedua, sedangkan bentuk maupun kualitas rumah 
menjadi prioritas terakhir. Yang terpenting bagi mereka adalah tersedianya rumah untuk berlindung dan istirahat dalam upaya mempertahankan hidupnya.

Begitu juga Santoso (2002) dalam Kurniasih (2007) yang mengungkapkan bahwa rumah bagi masyarakat yang berpenghasilan rendah adalah : (Hutapea, 2012)

A. Dekat dengan tempat kerja atau di tempat yang berpeluang untuk mendapatkan pekerjaan, minimal pekerjaan di sektor informal.

B. Kualitas fisik rumah dan lingkungan, tidak penting sejauh masih dapat menyelenggarakan kehidupan.

C. Hak-hak penguasaan khususnya hak milik atas tanah dan bangunan, tidak penting. Yang penting adalah tidak diusir atau digusur, sesuai dengan cara berpikir mereka bahwa rumah adalah sebuah fasilitas.

\subsection{PERATURAN DAN KRITERIA MBR DALAM MEMPEROLEH RUMAH}

Menurut “PERATURAN MENTERI PEKERJAAN UMUM DAN PERUMAHAN RAKYAT REPUBLIK INDONESIA NOMOR 1 TAHUN 2021 TENTANG KRITERIA MASYARAKAT BERPENGHASILAN RENDAH DAN PERSYARATAN KEMUDAHAN PEMBANGUNAN DAN PEROLEHAN RUMAH”

Pasal 1

Dalam Peraturan Menteri ini yang dimaksud dengan:

1. Masyarakat Berpenghasilan Rendah yang selanjutnya disingkat MBR adalah masyarakat yang mempunyai keterbatasan daya beli sehingga perlu mendapat dukungan pemerintah untuk memperoleh rumah.

2. Rumah adalah bangunan gedung yang berfungsi sebagai tempat tinggal yang layak huni, sarana pembinaan keluarga, cerminan harkat dan martabat penghuninya, serta aset bagi pemiliknya.

3. Rumah Umum adalah Rumah yang diselenggarakan untuk memenuhi kebutuhan Rumah bagi MBR.

4. Rumah Swadaya adalah Rumah yang dibangun atas prakarsa dan upaya masyarakat.

5. Menteri adalah menteri yang menyelenggarakan urusan pemerintahan di bidang perumahan dan Kawasan permukiman. 


\section{Pasal 2}

1) Kriteria MBR merupakan indikator dalam menentukan masyarakat yang termasuk MBR.

2) Kriteria MBR sebagaimana dimaksud pada ayat (1) didasarkan pada besaran penghasilan.

3) Besaran penghasilan sebagaimana dimaksud pada ayat (2) ditentukan berdasarkan:

a. penghasilan orang perseorangan yang tidak kawin

b. penghasilan orang perseorangan yang kawin.

4) Penghasilan orang perseorangan yang tidak kawin sebagaimana dimaksud pada ayat (3) huruf a merupakan seluruh pendapatan bersih yang bersumber dari gaji, upah, dan/atau hasil usaha sendiri.

5) Penghasilan orang perseorangan yang kawin sebagaimana dimaksud pada ayat (3) huruf b merupakan seluruh pendapatan bersih yang bersumber dari gaji, upah, dan/atau hasil usaha gabungan suami istri.

6) Dalam hal kriteria MBR sebagaimana dimaksud pada ayat (1) digunakan untuk pembangunan atau perolehan Rumah dengan mekanisme tabungan perumahan rakyat, besaran penghasilan sebagaimana dimaksud pada ayat (3) huruf b ditentukan hanya berdasarkan penghasilan 1 (satu) orang.

7) Penghasilan 1 (satu) orang sebagaimana dimaksud pada ayat (6) merupakan seluruh pendapatan bersih yang bersumber dari gaji, upah, dan/atau hasil usaha sendiri.

\section{Pasal 3}

1) Besaran penghasilan sebagaimana dimaksud dalam Pasal 2 ayat (2) dihitung berdasarkan kemampuan membayar biaya pembangunan atau perolehan Rumah layak huni.

2) Besaran penghasilan sebagaimana dimaksud pada ayat (1) merupakan nilai penghasilan paling banyak untuk pemberian kemudahan perolehan atau bantuan pembangunan Rumah. 
3) Kemampuan membayar biaya perolehan Rumah layakhuni sebagaimana dimaksud pada ayat (1) dihitung dari angsuran pembiayaan perolehan Rumah Umum menggunakan:
a. suku bunga dan tenor tertentu; atau
b. marjin komersial dan tenor tertentu.

4) Kemampuan membayar biaya pembangunan atau perbaikan Rumah layak huni sebagaimana dimaksud pada ayat (1) dihitung dari:
a. angsuran pembiayaan pembangunan atau perbaikan Rumah Swadaya; dan/atau
b. nilai keswadayaan terhadap biaya pembangunan atau perbaikan Rumah Swadaya.

5) Angsuran pembiayaan pembangunan atau perbaikan Rumah Swadaya sebagaimana dimaksud pada ayat (4) huruf a menggunakan:
a. suku bunga dan tenor tertentu; atau
b. marjin komersial dan tenor tertentu.

\section{Pasal 4}

1) Biaya perolehan atau pembangunan Rumah layak huni sebagaimana dimaksud dalam Pasal 3 ayat (1) dihitung sesuai jenis Rumah yang diperoleh berdasarkan:
a. harga jual pemilikan Rumah Umum;
b. biaya perbaikan Rumah Swadaya; atau
c. biaya pembangunan Rumah Swadaya.

2) Harga jual Rumah Umum sebagaimana dimaksud pada ayat (1) huruf a meliputi:
a. harga jual Rumah tunggal;
b. harga jual satuan Rumah deret; dan
c. harga jual satuan Rumah susun.

3) Harga jual pemilikan Rumah Umum sebagaimana dimaksud pada ayat (2) tanpa memperhitungkan pajak pertambahan nilai.

4) Harga jual Rumah Umum dan biaya pembangunan Rumah Swadaya sebagaimana dimaksud pada ayat (1) huruf a dan huruf c dihitung berdasarkan batasan luas lantai Rumah Umum dan Rumah Swadaya. 
5) Biaya perbaikan Rumah Swadaya sebagaimana dimaksud pada ayat (1) huruf b paling tinggi dihitung berdasarkan biaya pembangunan Rumah Swadaya.

\section{Pasal 5}

Besaran penghasilan MBR sebagaimana dimaksud dalam Pasal 3 ayat (2) dan batasan luas lantai Rumah Umum dan Rumah Swadaya sebagaimana dimaksud dalam Pasal 4 ayat (4) ditetapkan dalam Keputusan Menteri.

Pasal 6

1) Untuk mendapatkan kemudahan dan/atau bantuan pembangunan atau perolehan Rumah bagi MBR, masyarakat yang memenuhi persyaratan harus mengajukan permohonan sesuai dengan ketentuan peraturan perundang-undangan.

2) Persyaratan sebagaimana dimaksud pada ayat (1) meliputi:

a. berkewarganegaraan Indonesia; dan

b. memenuhi kriteria MBR.

3) Selain persyaratan sebagaimana dimaksud pada ayat (2), untuk mendapatkan kemudahan dan/atau bantuan pembangunan atau perolehan Rumah pemohon juga harus memenuhi persyaratan sesuai dengan ketentuan peraturan perundangundangan.

\subsection{ANALISIS PEMILIHAN LOKASI PEMBANGUNAN PERUMAHAN BAGI MASYARAKAT BERPENGHASILAN RENDAH}

Secara umum kondisi perumahan dan permukiman di Kota Palopo terdiri dari perumahan dengan konstruksi bangunan permanen, semi permanen dan temporer, yang masing-masing tersebar merata di hampir seluruh bagian wilayah Kota Palopo. Kawasan permukiman di wilayah Kota Palopo yang berkembang di daerah perkotaan umumnya telah terpola, tertata dan terencana dengan baik dan teratur, baik perumahan yang dikembangkan oleh pengembang swasta (developer) maupun perumahan yang dibangun oleh pemerintah, seperti lokasi perumahan PNS dan lain sebagainya. Sedangkan untuk kawasan permukiman di daerah pinggiran kota yang masih bersifat 
kedesaan, pola perkembangan kawasan permukiman umumnya berbentuk berkelompok dan kurang terpola, kurang tertata dan kurang terencana dengan baik.

Sehingga pemilihan lokasi pemukiman diarahkan pada kawasan semi pinggiran dan pinggiran kota, dengan ketersediaan dan daya tampung lahan yang cukup memadai. Pembangunan dan pengembangan perumahan di Kota Palopo, diperlukan penataan kawasan dan penyiapan kawasan siap bangun (Kasiba/Lisiba), serta penyediaan sarana dan prasarana penunjangnya, sehingga lebih awal diperlukan pembukaan akses jalan yang menghubungkan ke lokasi-lokasi rencana pembangunan perumahan, sebagai salah satu daya tarik dan motivasi bagi masyarakat dalam penyediaan sarana permukiman.

Kebutuhan yang cukup mendesak adalah penyediaan infrastruktur seperti penyediaan air bersih, pembangunan jaringan drainase perkotaan, peningkatan kualitas jalan, pembangunan tempat pengolahan limbah dan sanitasi lingkungan, peningkatan penanganan persampahan perkotaan serta penanganan terhadap fasilitas penunjang perkotaan lainnya.

Konsep rumah yang dibangun bagi masyarakat berpenghasilan rendah yang memiliki penghasilan rendah akan dibangun dengan tipe 27 dengan konsep rumah inti tumbuh. Konsep rumah Inti Tumbuh merupakan pembangunan rumah yang diawali dengan luas lebih kecil (tipe 21, 22, dan 27). Rencana pembangunan rumah yang diawali dari luas yang lebih kecil ini kemudian dilanjutkan dengan pengembangan sesuai dengan kemampuan dan kepuasan dari masyarakat berpenghasilan rendah. Konsep rumah inti tumbuh ini dimaksudkan agar masyarakat berpenghasilan rendah memiliki kemampuan untuk membeli rumah karena konstruksi yang akan dibangun kecil. Sedangkan konsep rumah yang dibangun bagi masyarakat berpenghasilan rendah dengan penghasilan maksimal Rp 3.500.000,- akan dibangun rumah dengan tipe 36. Rencana pembangunan rumah bagi masyarakat berpenghasilan rendah golongan ini 
lebih kepada konsep rumah sederhana sehat dengan kemampuan untuk memiliki rumah yang lebih tinggi. 


\section{BAB III \\ METODE PENELITIAN}

\subsection{JENIS PENELITIAN}

Penelitian ini meliputi perencanaan pembangunan perumahan bagi masyarakat berpenghasilan rendah di Kota Palopo dengan menggunakan metode kuantitatif. Metode kuantitatif merupakan penelitian yang menggunakan asumsi-asumsi pendekatan positivist (Prasetyo \& Jannah, 2005). Posotivisme bersumber dari orientasi ilmu alam yang kajiannya diarahkan pada pengembangan teori, riset seperti ini mendasarkan pada fakta yang dapat diamati secara langsung dan percaya bahwa membicarakan hanya ada satu realitas tunggal (Prasetyo \& Jannah, 2005). Metode kuantitatif digunakan untuk mengetahui needs assesment dari masyarakat berpenghasilan rendah dalam pemenuhan kebutuhan perumahan, perhitungan kebutuhan ruang pembangunan perumahan, pemilihan lokasi dan arahan desain pembangunan perumahan.

\subsection{LOKASI PENELITIAN}

Penelitian ini dilaksanakan di Kota Palopo .

\subsection{PENDEKATAN PENELITIAN}

Pendekatan penelitian ini merupakan penelitian kuantitatif. Metode Penelitian Kuantitatif, sebagaimana dikemukakan oleh Sugiyono (2009: 14) dapat diartikan sebagai metode penelitian yang berlandaskan pada filsafat positivisme, digunakan untuk meneliti pada populasi/sampel tertentu, teknik pengambilan sampel pada umumnya dilakukan secara random, pengumpulan data menggunakan instrumen penelitian, analisis data bersifat kuantitatif/statistik dengan tujuan untuk menguji hipotesis yang telah ditetapkan.

\subsection{TEKNIK PENGUMPULAN DATA}

Teknik pengumpulan data digunakan untuk mengumpulkan data sesuai tata cara penelitian sehingga diperoleh data yang dibutuhkan. Menurut Sugiyono (2012 : 224), teknik pengumpulan data merupakan langkah yang paling strategis dalam penelitian, 
karena tujuan utama dari penelitian adalah mengumpulkan data. Teknik pengumpulan data dalam penelitian ini menggunakan teknik Study Pustaka,Study Dokumen.

A. Study Pustaka

Studi pustaka juga merupakan salah satu teknik pengumpulan data yang juga banyak digunakan oleh para peneliti. Teknik pengumpulan data studi pustaka dilakukan dengan cara mengumpulkan data yang relevan atau sesuai yang dibutuhkan untuk penelitian dari buku, artikel ilmiah, berita, maupun sumber kredibel lainnya yang reliabel dan juga sesuai dengan topik penelitian yang dilakukan.

B. Study Dokumen

Teknik pengumpulan data ini dilakukan dengan mengandalkan dokumen sebagai salah satu sumber data yang digunakan untuk melengkapi penelitian. Dokumen yang digunakan dapat berupa sumber tertulis, film, dan gambar atau foto. 


\section{DAFTAR PUSTAKA}

[1] Fisu, A. A. (2018). ANALISIS LOKASI PADA PERENCANAAN TERMINAL TOPOYO MAMUJU TENGAH. PENA TEKNIK: Jurnal IImiah IImu-IImu Teknik, 3(1), 1-12.

[2] FISU, A. A. STUDI AWAL LOKASI RENCANA PELABUHAN DI TELUK PRIGI KABUPATEN TRENGGALEK.

[3] Fisu, A. A. (2019). 17 Tahun Kota Palopo: Kota, Manusia dan Para Penggerak.

[4] Nurhijrah, N., Fisu, A. A., Marzaman, L. U., \& Hafid, Z. KONSEP PENATAAN KAWASAN LALEBBATA SEBAGAI KAWASAN HERITAGE DI KOTA PALOPO. Jurnal Arsitektur ZONASI, 4(1).

[5] Natsir, R. (2018). EVALUASI KINERJA SIMPANG BERSINYAL DI KOTA PALOPO. PENA TEKNIK: Jurnal IImiah IImu-IImu Teknik, 1(1), 95-100.

[6] Fisu, A. A. (2020). Analisis Perencanaan Pengembangan Fasilitas Terminal Khusus PLTU Nagan Raya Aceh.

[7] Marsus, B., Indriani, N. K., Darmawan, V., \& Fisu, A. A. (2020). PENGARUH PANJANG INFRASTRUKTUR JALAN TERHADAP PDRB DAN PERTUMBUHAN EKONOMI KOTA PALOPO.

[8] Fisu, A. A. (2016). Analisis dan Konsep Perencanaan Kawasan Pelabuhan Kota Penajam Sebagai Pintu Gerbang Kab. Penajam Paser Utara kalimantan Timur. PENA TEKNIK: Jurnal IImiah IImu-IImu Teknik, 1(2), 125-136. 